\title{
REPORT OF AN INVESTIGATION OF HIGH SCHOOL PHYSIOGRAPHY.
}

By Charles Emerson Peet, Lewis Institute, Chicago, Chairman of Committee.

(Continued from the April Number.)

In What Respect Are the Results Least Satisfactory?

In answer to the question, "In what respect are the results in high school physiography least satisfactory?" the following answers were received: (The numbers in parentheses indicate the number of replies).

1. Student's knowledge of physiography superficial and not specific and definite.

2. In the inability of students to apply the knowledge in the interpretation of out-door phenomena, in the bookishness of the knowledge and the failure to realize that the subject deals with realities. (11)

3. In the development of reasoning powers, powers of deduction, ability to study. Memory loaded, but thinking powers untrained. (7)

4. In the failure to develop interest in the subject, or an appreciation of relations of phenomena of climate to life, to processes to results.

5 . Not satisfactory in any respect.

Reasons for Unsatisfactory Results.

In answer to the question, "What are the chief reasons for these unsatisfactory results?" the following reasons were given:

1. "There is not only lack of uniformity of aim, but worse than that a lack of aim, and, of course, lack of result. It is the old story-teachers in the other branches are expected to know their strbjects, not so yet with physiography."

2. "Perhaps it is due to not enough field work, to not visualizing the stages of the process. The text is often learned when it is not understood.

"The teacher of physiography has difficulties without a thorough understanding of the subject and a wide actual knowledge of field interpretation obtained from field work, topographic mapwork and travel."

3. "It is too apt to be true that the high school teacher attempts so much that the immature student is confused and mystified, with the result that a positive dislike of the subject is engendered. This cannot help having a very unfortunate influence 
upon the bearing of such a student when he engages in the more advanced college work. It sometimes takes several months to secure the interest of such a student, and his high school work is worse than useless."

4. "It is practically impossible to pick out any one thing in which the results are especially unsatisfactory-they are so generally bad. The worst trouble with the high schools is that poorly trained teachers, who know nothing about physiography, attempt to teach everything under the sun in the name of this science. What the teachers need is common sense, and knowlcdye of the subject. Then let them use a good textbook, cut out most of the foolish laboratory work, put plenty of field work in, and a reasonable amount of well-selected outside reading."

5. "There are two chief reasons for these unsatisfactory resuits. One is, that physiography is usually taught in the first year of the high school, when, of course, no subject which does not proceed farther is likely to be well grasped by the student. The second reason is that the subject is often taught by teachers who are totally unqualified to give good instruction in this line. With the exception of some of the high schools in the larger cities, there seems to be very little attempt to get teachers of physiography who are well prepared, and in the arrangement of the program, this subject is likely to go to the newest and least experienced teacher, or else is turned over to a science teacher, whose chief interest is other than physiography."

6. "Most science textbooks are written from the point of view of the technical scientists rather than that of the teacher, and they do not appeal to the ordinary boy or girl. There are too many subjects half tatight in the graded and high schools."

\%. "In the high schools physical geography if taught at all is in the first year, and, as State Inspector of high schools, I have had an opportunity to see something of its value. There can be no question that as now taught, following standard texts the work is of little value. It is not good discipline and comes down pretty largely to textbook recitation and memory drill, in which respect it is somewhat less valuable than Latin or other subjects with more definite method. The result is that school men, who naturally are keenly interested in having science in the high schools, are looking for something to replace physiography; and some very satisfactory results have been secured by introducing an extremely elementary course in general science dealing primarily with physical and chemical principles. 
"To my mind the trouble comes in the content of physiography as represented by texts. It is altogether too geological. I an satisfied that if the topics treated under the head of physical geography should be confined to those which have direct bearing on man (for example, water supply, soil, forestry, weather, etc.) with a rather full development of the influences which these things exert on man, the subject would be found interesting and could be taught by the type of teacher with which we have to deal. The satisfactory results obtained in botany, zoölogy, physics, and chemistry in our schools would seem to indicate that the difficulty with physiography is not so much a matter of teaching or a disposition on the part of the student to avoid science, but that the subject as commonly outlined is inappropriate for first year high school students."

8. "The unsatisfactory results of high school physiography are, to my thinking, largely due to what is really a too advanced subject taught by persons who understand it imperfectly."

9. "Judging from my own experience and observation, I should say that the chief cause for poor results in the teaching of physiography in the high schools, at least in the West, is the lack of specially trained teachers. Many of those who are teaching the subject in this state and California had never even studied it before teaching it ; and I have only occasionally met a teacher who has had any special training in that line. These statements are based (1) on my observations while teaching this subject, in both high school and university; (2) on my university experience with pupils from the high schools, and (3) on my observations in the schools, as one of the high school examiners for the university in this state."

10. "I have looked over the field in nearly every school tributary to this Normal and without an exception the fault is largely in the teaching. 'Usually the person 'having a vacant hour' is given the class in physical geography. Most of the teachers, in fact practically all the teachers are absolutely without any special preparation to teach the subject. As might be expected such teachers do not feel the need of adequate equipment and as a result the high schools have almost no laboratory equipment for the work:"

11. "The principal trouble with high school physiography is that it is generally treated as a textbook science. There is not enough laboratory and field work given in connection with it. In case physiography precedes the study of the physical sciences, 
it should be used chiefly to lead the pupil into scientific methods of procedure. Laboratory work of a simple kind ought to be given in order to give the student some scientific methods. As it is now almost nothing of this kind is done. In case of physiography following the study of the physical sciences, there should be more of an effort made to apply the principles of the other sciences to the study of the earth-for instance in physiography here at the college, I frequently give two weeks in the laboratory on weathering alone. I very seldom find a high school student who knows what oxidation is, or seems to have any conception of what is the effect of alternate heat and cold on a rock surface, and yet this is a most elementary physical matter. There is not enough practical application of the textbook to the facts of physiography."

12. "The course in high school physiography is generally unsatisfactory because of lack of laboratory facilities and apparatus. Few high schools are properly equipped for teaching the subject as it should be taught. Students are liable to form a dislike for the subject if an attempt is made to teach it without proper illustrative material."

13. "Unprepared teachers with only a book interest in the subject. Remedy - good teachers of fair degree of preparation, with a iove for the work, and a desire to put the boys and girls in touch with their common everyday environment of air, land, and water, without specially 'preparing' or 'laying a foundation' for later sciences or for college, just to get the boys and girls to understand the things around them, not to 'prepare for life,' but to help them to live a fuller, richer, life while boys and girls."

Summary of the reasons given for poor results :

1. No definite aim.

2. High schools attempt too much:

a. There are too many subjects.

b. Too many things are taught under the name of physiography.

3. High schools are attempting the impossible.

4. Immaturity of the student and his ignorance of physical science and ordinary geography.

5. The subject is too difficult and abstract, and is inappropriate for first year work. The texts are too technical.

6. Teachers do not understand the subject.

\%. Teachers do not have an interest in the subject.

8. Teachers are untrained. 
9. There is too little field work. The work is too bookish.

10. The laboratory and illustrative material are inadequate.

11. Facts instead of principles are taught. Descriptions instead of solutions of problems are required.

SOME VIEWS OF HIGH SCHOOL MEN.

In order to get at the high school man's views, letters were sent to over two hundred instructors in physiography asking what in their opinion are the reasons for the apparently poor results. A few answers follow:

1. "I am afraid that the teaching of physiography is not apparently poor, but really so; and the reason is chiefly lack of preparation on the part of the teachers. In our own state, five years ago, among 180 persons teaching earth science there were just three who had done their college work along that line, and not more than twenty-five who had studied the subject in a decent college. That condition would not be tolerated in any other science. Then, too, the college men are just as often at fault as the student. They make no effort, for the most part, to use the foundation laid in secondary schools."

2. "Physiography is taught in the Freshman year and many students never refer to it again in high school. Even when they take other sciences it is scarcely referred to, especially as geology is seldom taught in our high schools. For four years I have given a course in general science. For five years previous to this I had given physiography. I consider general science better for a foundation course. After that, physiography may be given in such a manner as to dignify it as a science not as a foundation course. The pupils come to us with no previous foundation except in a few cities where the grades do some real nature study."

3. "Every teacher overestimates the amount of knowledge he thinks a previous instructor should have made perpetual in the minds of students. The high school teacher blames those in the grades and in turn the grade teachers attribute their inability to impart lasting knowledge to home conditions. The college man must consider that the high school student has probably not had more than a semester of physiography and that many years before: moreover it was forced upon him before he was old enough or had science foundation enough, to grasp the subject properly. There is no doubt in my mind that students enter universities sadly lacking in common sense physiographic knowledge. Nor can this be remedied until school authorities are made first. to 
realize the importance of the subject; second, to engage competent instructors and pay respectably for the instruction; third, to establish certain prerequisites for the course."

4. "The reason for the poor results of high school physiography lies mostly in the limitations of the teachers. I have sat in three meetings during the past three years and have listened to the discussions of "The Problem of Physical Geography,", and each time the conclusion was reached that physical geography is a most difficult subject to teach and that the poorest teachers are teaching it."

5. "I have yet to find a boy or girl, who, having chosen the science course, abandoned it after taking physical geography. The results of the high school physiography ought not to be poor and I cannot quite believe they are unrecognizable later in college courses."

RESPONSIBILITY: FOR POOR RESULTS.

Of all the reasons for poor results the most commonly mentioned is poor teaching, and teachers poorly trained and poorly equipped in the knowledge of physiography. Twenty-six of the college men give these reasons. The questionnaire sent the college instructors included the question, "Is it reasonable to expect that young people fourteen or fifteen years old should retain much of the knowledge which they gained in the study: of physiography but have not used for the three or four intervening years?" Thirty-eight answered, "No," and eleven answered, "Yes." If it is not reasonable to expect the young people to retain much of the knowledge which they gained in the study of physiography in the early high school years, should the responsibility for the student's lack of knowledge of physiography be assigned so unreservedly to poor teachers and poor teaching? If the poor results are in the development of thinking power the physiography instructor can hardly be held responsible at the most for more than about seven per cent of it, for physiography is only one of fifteen credits presented for entrance to college and the time given to it is not more than seven per cent of the entire time given to the high school training: For the poor results in thinking power the entire high school must be considered responsible rather than the instructors in one subject.

The remedy for the poor results of poor teachers is obvious. The poor teachers should be given opportunity to become good teachers. The apparently poor results of the good teachers and especially their good results may profitably be given further 
study. The truth of the matter is, that we do not know how much of the good results recognized when the student gets to college are because of (1) the exceptional ability of the individual; (2) exceptional home influences; (3) skillful teaching; (4) ordinary teaching under fortunate circtumstance; (5) knowledge made fresh by reeent review, or acquired by a course taken in the maturity of the late high school years; (6) continuity of the science course and co-operation among the instructors in co-ordinating the subjects so that the student has used in later years what he learned in the earlier years of the course, or (7) a combination of these factors. The first two factors mentioned are beyond school control. It may be a satisfaction for us to know that good results are produced with these individuals but we cannot profit by this knowledge to improve our results. We know that skillful teaching late in the high school sometimes produces recognizable results. We do not know that skillful teaching in the first year of the high school ever produces, with the ordinary student, results recognizable in college.

The immaturity of the student, a lack of any previous experience in the study of science, and the lack of a follow-up system to give the student a chance to use his knowledge are recognized as some of the causes for poor results where the subject is taught in the first year.

Nine years ago a paper was read before this section ${ }^{4}$ in which expansion of the course in physiography downward into the underlying physical sciences and upward into the study of geography was urged because of the interests of the young people and for the sake of improving the work in physiography. The recent introduction of elementary science courses, and courses in general geography shows that the need of this expansion has been widely felt. The value to the physiography of the elementary science course is mentioned by several of the college men, and its value for other courses is mentioned in the replies of several of the high school principals. If the physiography has lost ground because of the introduction of courses in elementary science, the leaders in our subject are alone responsible. The field was ours. We might have held it had they been willing to go outside the strictly orthodox limits of the subject. With the increase of Junior high schools and the introduction into them of 'a year or two of elementary science in what is now known as the seventh and eighth grades, we may, in the future, find ourselves in a po-

4 See School Science and Mathematics, Volume 7 , page 425. 
sition to produce good results in the ninth grade without going outside the strict limits of our subject. It will be just as necessary then as it is now to give the student an opportunity to use, in the study of geography, the knowledge he has acquired with us. It will be just as necessary then as it is now for us to secure the co-operation of our fellow teachers in science and in history, if we are to secure the best results. We have not secured this co-operation and the result has been that both knowledge and methods which we have attempted to teach have soon faded.

As teachers of the science which is now commonly in the first year of the high school, we are more interested in the work of the committee on a "Unified Science Course" in the high school than any other science teachers. We have more to gain through unification and co-ordination of the high school sciences than others. The work of the committee, of which Mr. James H. Smith and Mr. C. E. Spicer of this section are members, should not only be received with an open mind but should have our hearty support.

If the science work were unified as it should be there is reason to believe that both the methods and the knowledge acquired in the first year would be firmly established by the fourth year of the high school instead of having disappeared.

\section{WHY SHOULD LIGHT COME FROM THE LEFT SIDE?}

The well known fact that, when using the eyes for any near work, the illumination should come from the left side rather than the right is often disregarded. Let any one who considers the matter of little importance once demonstrate to himself the difference and he will never forget it. Take a pencil and paper and try to write while in such a position that the light will fall from the right side. The shadow of the hand or pencil or both is thrown on the paper in such a way as partly to cover the characters one is making. This necessitates a closer viewpoint and a conscious strain on the eyes. Now let the position of the writer be reversed so that the light falls on the work from the left side. He will notice that the shadows fall away from the work he is doing and leaves the field unobscured. In making the change he cannot help but notice the feeling of ease that immediately is experienced by the eyes. This applies to any other kind of near work in which the fingers work under the guidance of the eyes. This fact should be remembered in planning schoo!rooms, workrooms, offices and any places where steady close work is to be performed. 